\title{
Gender-Role Attitudes in Taiwan and Coastal China
}

\author{
Su-hao Tu, Pei-shan Liao, Ying-hwa Chang
}

\begin{abstract}
This paper examines patterns of gender-role attitudes and the factors producing them based upon the supposition that social and economic changes are the main determinant of individual beliefs. This comparative study, using empirical data from the East Asian Social Survey of 1996-97, focuses on Taiwan and coastal China. Latent Class Analysis revealed generally similar patterns of gender-role attitudes between Taiwan and China. Residents of coastal China were found to be more likely than Taiwanese to hold traditional attitudes toward gender roles. Multinomial logistic regression analysis of the two data sets revealed, moreover, that education was consistently significant across the two societies but more pronounced in Taiwan. Diverse findings on gender, birth cohort, childbearing, and parental effects between Taiwan and China suggest that socio-economic development, to some degree, differentiate individual gender-role attitudes regardless of the shared cultural heritage.
\end{abstract}

Key words: gender-role attitudes, Latent Class Analysis, societal differences

2006, Japanese Journal of Family Sociology, 17(2): 95-109

\section{INTRODUCTION}

Taiwan and China share a similar cultural heritage but have experienced different socioeconomic development, affecting gender relations. In Taiwan, women's labor participation, mostly in the informal sector, has increased since export-led industrialization but was not formally recognized until the 1990s. In China, socialist policies had radically increased women's labor participation and narrowed the gender gap in income. The introduction of market economics to China that began in the late 1970s, however, diminished many Chinese women's access to employment opportunities (Abbott, et al., 1995: Rai, 1995: Thoburn and Howell, 1995). Taiwanese now experience a more individualist occupational system than the Chinese (Tang and Parish, 2000).

Education has been essential for the achievement of high social-economic status in Taiwan (Hsieh and Burgess, 1994). In China, women's access to formal education has fluctuated greatly; women were encouraged to pursue higher education during the Cultural Revolution but have often been discouraged from doing so since the 1970s (Rai, 1995: Tang and Parish, 2000). China's one-child policy, announced in 1979, has brought considerable pressure on parents to raise a son to continue the patrilineal line. While China's communist state has provided a limited openness for women to have independent civil participation, the women's movement in Taiwan has

Su-hao Tu: Associate Research Fellow in Center for Survey Research, Research Center for Humanities and Social Sciences, Academia Sinica

Pei-shan Liao: Assistant Research Fellow in Center for Survey Research, Research Center for Humanities and Social Sciences, Academia Sinica

Ying-hwa Chang: Research Fellow in Institute of Sociology and the Director of Research Center for Humanities and Social Sciences, Academia Sinica 


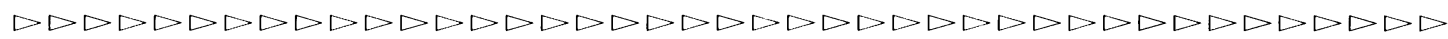

had increased success in promoting gender equality since the 1970 s.

Life experiences since the 1950s imply different development of gender consciousness in the two societies. Gender equality has progressed steadily in Taiwan, while gender egalitarianism, a hallmark of socialist policy, has in fact regressed under post-socialist policies during recent decades in China (Hsieh and Burgess, 1994). The progression in Taiwan and regression in China, which have proceeded at disparate paces, raise several research questions. Are there different patterns of genderrole attitudes between Taiwan and China? What are the important factors explaining the patterns of gender-role attitudes? To what extent does the contextual effect on the patterns of gender-role attitudes differ between Taiwan and China?

\section{LITERATURE REVIEW}

Until the late 1990s, when greater weight began to be ascribed to social difference, the literature emphasized the influences of human capital and family socialization. Social difference was not considered central to gender-role beliefs. The following section reviews and discusses the literature from the perspectives of resource exchange, family socialization, gender and cohort effect, and social changes.

\section{Resource Exchange}

Previous studies have examined women's views of ideal gender roles in the context of tension between the spheres of reproduction and production (Bielby and Bielby, 1984: Panayotova and Brayfield, 1997). The participation in the labor force provided concrete examples to modify women's traditional perspectives on equality at work, while employment experience and personal income represent financial independence of others. The positive association between employment status and egalitarian attitudes was found to be significant among both women and men (Cassidy and Warren, 1996: Mason and Lu, 1988: Plutzer, 1988: Tallichet and Willits, 1986: Wilson and Smith, 1995). The positive effect of personal income on egalitarian attitudes, however, was found to be more impor- tant for women than for men (Baxter and Kane, 1995: Mason, et al., 1976). No evidence has concluded that lower-income men hold less egalitarian attitudes than higher-income men (Wilkie, 1993).

Education is essential to raising people's awareness of and access to new beliefs. A positive correlation exists between education and egalitarian attitudes (Dugger, 1991: Plutzer, 1988: Wilson and Smith, 1995). Although previous research has focused primarily upon market societies, it is still plausible to expect the positive effects of employment, income, and education on gender-role attitudes in a socialist society such as China.

\section{Family Socialization}

Families play a major role in shaping an individual's views. Individuals may respond and adjust to new values as their family members encounter new changes from outside (Thornton and Lin, 1994). Accordingly, marriage and childbearing have been linked to greater individual dependence upon family and, especially, female dependence upon males. Having marriage experience was found to reduce the likelihood of possessing egalitarian opinions regarding gender roles (Baxter and Kane, 1995: Panayotova and Brayfield, 1997: Wilkie, 1993). Some studies found that childbearing decreases women's egalitarian attitudes in terms of the presence of children (Baxter and Kane, 1995: Mason, et al., 1976), while others found no significant effect, considering both the presence and number of children (Panayotova and Brayfield, 1997: Plutzer, 1988: Tallichet and Willits, 1986).

The family is the unit in which the younger generation is socialized. Variables associated with family socialization included parental background (e.g., parental education and employment status) and family characteristics (e.g., family size) (Kulik, 2002). Those whose fathers were professional or clerical workers tended to hold modern gender-role attitudes in studies comparing Japanese and American married women (Yamaguchi, 2000a, 2000b). The father's education was found to play a more important role than the mother's in determining children's gender-role attitudes 


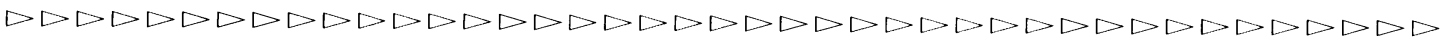

(Tallichet and Willits, 1986: Thornton, et al., 1983). Those who grew up in a nuclear family in Taiwan tend to hold egalitarian attitudes (Huang, 1998). While China and Taiwan have experienced a shift toward non-familial modes of organization, the extent to which family policies may produce diverse changes of gender-role perceptions between Taiwan and China remains of interest for research.

\section{Gender and Cohort}

People are socialized to fulfill prescribed gender roles based on the division of masculinity and femininity. Cultural pressure, personal experience, and paid employment are corollaries of gender ideology (Lott, 1997). Women's entry into the labor force results in a roleswitch from the private sphere to the public one. Male role change, however, does not usually keep pace with women's role shift (Wilkie, 1993: Yi and Kao, 1986). Under the age-old patriarchal gender roles, men are less likely than women to support egalitarian attitudes (Panayotova and Brayfield, 1997).

Such gender differences have already been demonstrated (Brewster and Padavic, 2000: Katsurada and Sugihara, 1999: Rice and Coates, 1995). The size of gender gap may vary with culture and national context (Baxter and Kane, 1995), which raises the question of to what extent the size of the gender gap in gender-role attitudes differs between Taiwan and China.

Older cohorts are socialized to hold more traditional values and were found less likely to support egalitarian attitudes (Ciabattari, 2001: Brewster and Padavic, 2000: Yamaguchi, $2000 \mathrm{~b})$. Whether the cohort effect manifests itself as a linear association with gender-role attitudes across different social contexts needs further examination. Compared with the same cohort in Taiwan, the period from the establishment of the People's Republic of China in 1949 to the beginning of the Cultural Revolution in the mid 1960s reflects a radical cohort experience of gender equality (Hsieh and Burgess, 1994: Jacka, 1997). As such, the birth cohort is expected to have a fluctuant effect in China but a linear effect in Taiwan.

\section{Social Changes}

Differential social conditions are suggested to produce distinct personal beliefs through state policies, such as industrialization, urbanization, and family planning (Lott, 1997). Those who are exposed to industrialization tend to be non-domestic-value-oriented (Thornton and Lin, 1994: Jacka, 1997). Similarly, urbanization moderates individual beliefs toward egalitarianism through the increase of personal networks and international contacts. The emergence of capitalism in a socialist society could be expected, however, to decrease gender egalitarianism (Tang and Parish, 2000).

Previous research indicated varying levels of egalitarian attitudes across five industrialized nations (Baxter and Kane, 1995). While gender-role attitudes were found more traditional in socialist-market Hungary than in free-market America, Chinese students were found mostly but not necessarily more traditional than Taiwanese students toward marital-role attitudes (Hsieh and Burgess, 1994: Panayotova and Brayfield, 1997). Whether gender egalitarianism decreases with the emergence of capitalism requires an extensive examination of the general public in Taiwan and in China.

In doing so, this paper aims to examine gender-role attitudes from the perspective that integrates on the societal, family, and individual levels. The hypotheses are as follows. At the individual and family levels, personal and parental human resources promote egalitarian attitudes toward gender roles. Marriage, childbearing, large family size, and older cohorts result in traditional gender attitudes. Women are more likely than men to have modern gender attitudes. Also, gender and personal income would exert main effects as well as an interaction effect on gender-role attitudes.

At the societal level, similar patterns of gender-role attitudes are expected, but with more egalitarianism in Taiwan than in China. The factors underlying gender-role attitudes are assumed to be similar between Taiwan and China except for birth cohort, employment, education, and childbearing experience. In 


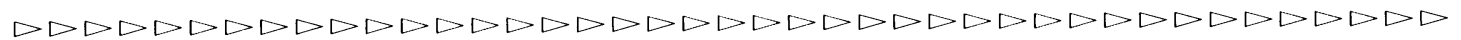

Taiwan, family planning has been advocated but not mandated, and female labor participation has been a consequence of economic upgrading and its concomitant educational expansion. Educational and occupational effects would therefore be more important for Taiwanese. Nevertheless, in China, the restrictive one-child and job-allocation policies, which have been carried out more strictly in rural areas than in urban areas during different periods, can be expected to produce significant cohort and regional effects.

\section{DATA AND MEASUREMENT}

The data for Taiwan, which feature an islandwide representative sample, were collected in one of the two surveys of the 1996 Taiwan Social Change Survey. The data for China come from the 1997 East Asian Social Survey of coastal China, which was conducted as a separate part of the Taiwan Social Change Survey. The coastal areas of China, including 18 cities and their neighboring areas, were selected in order to parallel the urbanized environment of Taiwan and were biased by being overrepresented with urban respondents. Adult respondents were selected by using a multistage probability sampling and were interviewed face to face.

The respondents were asked whether they agree with five statements concerning genderrole attitudes: (A) Husbands should work outside the home, and wives should maintain the home, (B) Women naturally take much better care of families than men do, (C) A woman achieves through her husband's career achievements, (D) Women should raise children to have a complete and happy life, and (E) Men can have a complete and happy life without raising children. The answers to the items A through E were categorized as (1) strongly disagree, (2) disagree, (3) agree, (4) strongly agree, or (5) no opinion. Positive responses to the first four statements and a negative response to the fifth imply a traditional/genderinequality orientation.

Dichotomous variables were created by combining "strongly agree" with "agree," "strongly disagree" with "disagree," and "no opinion" with higher proportion. "No opinion" toward item $\mathrm{E}$ in the Taiwanese data was, however, an independent category because its percentage was close to ten. Those who did not respond to three or more of the five items were excluded. A total of 2,758 and 2,925 completed interviews from Taiwan and coastal China, respectively, were included in the final analysis.

Current occupation, a human-resource variable, was a respondent's occupational status at the current job or the latest job. The original categories were regrouped into six major categories based on levels of professional and technological skill. These categories included administrative staff and managers, professionals, technological workers, manual workers, farmers, and currently unemployed and others (e.g., students and homemakers). Dummy variables were created with technological workers as the reference category. Other human-resource variables are personal annual income (in US $\$ 1,000$ ) from current job and education (in years).

Socialization variables include marital status (married or living with a partner, versus unmarried), father's occupation (measured in the same way as the respondent's current occupation), father's and mother's education (in years), family size (the number of family members living with the respondent), and the number of children. Age was grouped mainly based on cohort experience in China. Using 1949 (when China officially became a communist society) and 1965 (the beginning of the Cultural Revolution) as cutoff points, three birth cohorts were defined as those born (1) in 1949 or before, (2) between 1950 and 1965, and (3) in 1966 or after. Urban experience was measured by whether a respondent had lived in a city before the age of 15 .

Latent Class Analysis (LCA), which reveals intra-group heterogeneity in response patterns, was employed to identify major response patterns of gender-role attitudes. The results of LCA were used as the dependent variable. Multinomial logistic regression was used to examine the effects of the independent variables on the types of gender-role attitudes. 
TABLE 1. UNIVARIATE STATISTICS

\begin{tabular}{|c|c|c|c|c|}
\hline & \multicolumn{2}{|c|}{ Taiwan } & \multicolumn{2}{|c|}{ China } \\
\hline & Mean (S.D.) $/ \%$ & $N$ & Mean (S.D.) $/ \%$ & $N$ \\
\hline 1. Personal occupation & & 2,757 & & 2,854 \\
\hline (1) Administration & 3.9 & 107 & 5.1 & 149 \\
\hline (2) Professional worker & 17.7 & 488 & 9.6 & 279 \\
\hline (3) Technological worker & 14.1 & 390 & 38.6 & 1,127 \\
\hline (4) Manual worker & 29.5 & 813 & 32.1 & 938 \\
\hline (5) Farmer & 10.8 & 297 & 9.0 & 264 \\
\hline (6) Unemployed and others & 24.0 & 662 & 5.6 & 164 \\
\hline 2. Personal income ( 1,000 US\$) & $13.2(15.2)$ & 2,469 & $1.2(1.8)$ & 2,646 \\
\hline 3. Personal education & & 2,757 & & 2,896 \\
\hline (1) Primary school or less & 33.7 & 930 & 22.9 & 665 \\
\hline (2) Junior high school & 17.8 & 492 & 34.3 & 993 \\
\hline (3) Senior high school & 26.5 & 731 & 30.2 & 876 \\
\hline (4) College or beyond & 21.9 & 604 & 12.5 & 362 \\
\hline 4. Marital status & & 2,758 & & 2,925 \\
\hline (1) Married/living with partner & 87.7 & 2,419 & 91.1 & 2,665 \\
\hline 5. Father's education & & 2,600 & & 2,694 \\
\hline (1) Primary school or less & 75.4 & 1,961 & 71.0 & 1,914 \\
\hline (2) Junior high school & 9.2 & 239 & 14.6 & 393 \\
\hline (3) Senior high school & 9.5 & 248 & 8.4 & 226 \\
\hline (4) College or beyond & 5.8 & 152 & 6.0 & 161 \\
\hline 6. Father's occupation & & 2,585 & & 2,565 \\
\hline (1) Administration & 6.7 & 172 & 10.3 & 265 \\
\hline (2) Professional worker & 8.7 & 224 & 6.5 & 166 \\
\hline (3) Technological worker & 44.4 & 1,149 & 47.5 & 1,218 \\
\hline (4) Manual worker & 27.4 & 708 & 26.5 & 680 \\
\hline (5) Farmer & 11.6 & 301 & 8.1 & 207 \\
\hline (6) Unemployed and others & 1.2 & 31 & 1.1 & 29 \\
\hline 7. Mother's education & & 2,673 & & 2,756 \\
\hline (1) Primary school or less & 90.9 & 2,429 & 83.8 & 2,309 \\
\hline (2) Junior high school & 5.5 & 147 & 9.4 & 258 \\
\hline (3) Senior high school & 2.6 & 70 & 5.3 & 146 \\
\hline (4) College or beyond & 1.0 & 27 & 1.5 & 43 \\
\hline 8. Total no. of children & & 2,758 & & 2,925 \\
\hline (1) Zero & 16.2 & 446 & 13.4 & 393 \\
\hline (2) One & 10.3 & 284 & 50.8 & 1,487 \\
\hline (3) Two & 31.9 & 881 & 19.7 & 577 \\
\hline (4) Three & 26.9 & 743 & 9.6 & 280 \\
\hline (5) Four or more & 14.7 & 404 & 6.4 & 188 \\
\hline 9. Mean family size (person) & $4.89(2.08)$ & 2,758 & $3.76(1.53)$ & 2,925 \\
\hline 10. Age & $40.2(9.1)$ & 2,758 & $42.2(11.2)$ & 2,925 \\
\hline 11. Birth cohort & & 2,758 & & 2,925 \\
\hline (1) Born in 1949 or before & 24.7 & 682 & 32.9 & 962 \\
\hline (2) Born 1950-1965 & 54.9 & 1,514 & 45.6 & 1,335 \\
\hline (3) Born in 1966 or after & 20.4 & 562 & 21.5 & 628 \\
\hline 12. Gender & & 2,831 & & 3,013 \\
\hline (1) Male & 51.3 & 1,452 & 50.6 & 1,525 \\
\hline 13. Urban experience (yes) & 49.7 & 2,758 & 70.3 & 2,925 \\
\hline
\end{tabular}

Note: 1 . S.D. $=$ Standard Deviation, $2 . \mathrm{N}=$ valid cases, 3 . Number in the parentheses is standard deviation. 


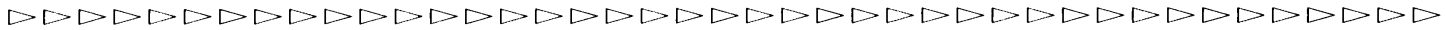

RESULTS

\section{Sample Descriptions}

Concerning human resources, the most frequently reported occupation among the Taiwanese respondents was manual worker (29.5 percent), followed by unemployed or other ( 24 percent), professional worker (17.7 percent), and technological worker (14.1 percent) (Table 1). In contrast, most of the Chinese respondents were technological workers (38.6 percent) and manual workers (32.1 percent). The percentage of the respondents with a high school degree (junior and senior high schools) in China was higher than that in Taiwan, while there were more respondents with primary school educations and college degrees in Taiwan than in China. The Chinese respondents had much lower annual income than the Taiwanese respondents.

The Chinese respondents were, on average, two years older than the Taiwanese respondents, with the highest proportion of respondents born between 1950 and 1965. Both data sets showed similar proportions of females who are married or living with a partner. Similar patterns of father's education were found between the Taiwanese and Chinese data. The respondents in both societies indicated low paternal educational attainment, with more than 70 percent completing no more than primary school. Mother's educational achievement in China, however, was found to be higher than in Taiwan. About 16 percent of the Chinese respondents' mothers had junior high school or higher degrees, while fewer than 10 percent of the Taiwanese respondents reported so. In addition, more than 40 percent of the respondents' fathers were technological workers, followed by manual workers. The Taiwanese respondents, on average, had one more family member than the Chinese respondents. Moreover, the Chinese respondents had a higher proportion having one child or no children (64.2 percent), while 58.8 percent of the Taiwanese respondents had two or three children. Slightly fewer than half of the Taiwanese respondents indicated that they lived in a city before they were 15 years old or before the survey was conducted, while 70 percent of the Chinese respondents did so.

\section{Latent Classes of Gender-Role Attitudes}

The cross-classification of the five dichotomous/trichotomous indicators of gender-role attitudes resulted in 48 and 32 response patterns for the Taiwanese and Chinese data, respectively, using the MLLSA program adapted by Eliason (1988). The distribution of gender-role attitudes for both data sets is reported in Table 2. The proportions of positive responses to five statements concerning gender-role attitudes ranged roughly from 30 percent to 91 percent in both of the samples. Also, almost 10 percent of the Taiwanese respondents had no opinion toward men's family life. Since agreement with items A through D and disagreement with item $\mathrm{E}$ indicated a more traditional orientation, most of the Taiwanese respondents reported traditional attitudes toward gender roles except for item A, with which about half of the respondents agreed. In contrast, the Chinese respondents indicated more traditional attitudes toward all statements.

Table 3 reports the goodness-of-fit statistics for four latent class models. The model with four latent classes fits both data sets well and thus was used to represent the latent class association among five items of gender-role attitudes. For each data set, a variable with four latent classes is used as the dependent variable for the analysis that follows.

In order to examine similarities among the patterns of gender-role attitudes across data sets, we compared the $L^{2}$ fit of a model, while equality restrictions were imposed on conditional probabilities across data sets to the $L^{2}$ fit of a model where the conditional probabilities were free to vary across data sets. The results indicated that it is statistically acceptable to impose the same estimated conditional probabilities upon all the response categories of item A and some categories of other items (results not shown) across data sets. By the same token, the similarities of latent class probabilities were examined. The tests rejected the assumption that the latent class probabilities did not vary across data sets; 
TABLE 2. DISTRIBUTION OF RESPONSES ON GENDER-ROLE ATTITUDES

\begin{tabular}{|c|c|c|c|}
\hline & Agree (\%) & Disagree (\%) & No opinion (\%) \\
\hline \multicolumn{4}{|l|}{ I. Taiwan $(N=2,757)$} \\
\hline $\begin{array}{l}\text { A. Husbands should work outside the home, } \\
\text { and wives should maintain the home. }\end{array}$ & $1,479(53.6)$ & $1,278(46.4)$ & - \\
\hline $\begin{array}{l}\text { B. Women naturally take much better care of } \\
\text { families than men do. }\end{array}$ & $2,207(80.1)$ & $550(19.9)$ & - \\
\hline $\begin{array}{l}\text { C. A woman achieves through her husband's } \\
\text { career achievements. }\end{array}$ & $2,514(91.2)$ & $243(8.8)$ & - \\
\hline $\begin{array}{l}\text { D. Women should raise children to have a } \\
\text { complete and happy life. }\end{array}$ & $1,894(68.7)$ & $863(31.3)$ & - \\
\hline $\begin{array}{l}\mathrm{E}^{1} \text {. Men can have a complete and happy life } \\
\text { without raising children. }\end{array}$ & $929(33.7)$ & $1,566(56.4)$ & $272(9.9)$ \\
\hline \multicolumn{4}{|l|}{ II. China $(N=2,882)$} \\
\hline $\begin{array}{l}\text { A. Husbands should work outside the home, } \\
\text { and wives should maintain the home. }\end{array}$ & $2,049(71.1)$ & $833(28.9)$ & - \\
\hline $\begin{array}{l}\text { B. Women naturally take much better care of } \\
\text { families than men do. }\end{array}$ & $2,229(77.4)$ & $652(22.6)$ & - \\
\hline $\begin{array}{l}\text { C. A woman achieves through her husband's } \\
\text { career achievements. }\end{array}$ & $2,599(90.2)$ & $282(9.8)$ & - \\
\hline $\begin{array}{l}\text { D. Women should raise children to have a } \\
\text { complete and happy life. }\end{array}$ & $2,068(71.9)$ & $810(28.1)$ & - \\
\hline $\begin{array}{l}\text { E. Men can have a complete and happy life } \\
\text { without raising children. }\end{array}$ & $870(30.2)$ & $2,010(69.8)$ & - \\
\hline
\end{tabular}

': Responses to this item were grouped into three categories. Other items were regrouped into two categories.

TABLE 3. GOODNESS OF FIT OF LATENT CLASS MODELS OF GENDER-ROLE ATTITUDES

\begin{tabular}{|c|c|c|c|}
\hline Number of latent classes & $L^{2}$ & d.f. & $p$ \\
\hline \multicolumn{4}{|l|}{ I. Taiwan } \\
\hline 1 & 843.98 & 42 & .000 \\
\hline 2 & 177.94 & 34 & .000 \\
\hline 3 & 54.59 & 27 & $<.005$ \\
\hline 4 & 19.83 & 21 & $>.500$ \\
\hline \multicolumn{4}{|l|}{ II. China } \\
\hline 1 & 958.78 & 26 & .000 \\
\hline 2 & 253.19 & 20 & .000 \\
\hline 3 & 34.84 & 15 & $<.005$ \\
\hline 4 & 8.93 & 9 & $>.500$ \\
\hline
\end{tabular}

thus, the differences of the latent class probabilities remained.

The estimated probability of the responses in each class is presented in Table 4 for both data sets. The Taiwanese respondents in Class I reported high probabilities of agreeing with items A through D and a low probability with item E. In other words, the respondents in Class I tended to have traditional attitudes toward gender division of household labor and to agree that children are important for a complete and happy life. The estimated probability for the Taiwanese respondents classified in Class I was .39. Class I was named the "Traditional type." The Taiwanese respondents in Class II had high probabilities of agreeing with items B, C, and E, and a very low probability of agreeing with item $\mathrm{D}$. The proportion of positive responses to item A was also higher than that of negative responses. The respondents in Class II were inclined to be traditional toward gender division of household labor but displayed a modern attitude toward not having children for a complete and happy life (items D and E). Eight percent of the respondents were classified in latent Class II, which was named the "Non-child-oriented traditional type." 
TABLE 4. LATENT CLASS PROBABILITIES OF GENDER-ROLE ATTITUDES

\begin{tabular}{lcccc|cccc}
\hline & \multicolumn{5}{c}{ Taiwan } & \multicolumn{5}{c}{ China } \\
\cline { 2 - 9 } Latent class $^{1}$ & I & II & III & IV & I & II & III & IV \\
\hline Class probability & .39 & .08 & .39 & .14 & .58 & .13 & .24 & .05 \\
\hline Response probability & & & & & & & & \\
A. Husbands should work outside the home & & & & & & & \\
$\quad$ and wives should maintain the home. & & & & & & & & \\
$\quad$ Agree & .95 & .66 & .26 & .09 & .95 & .66 & .26 & .09 \\
$\quad$ Disagree & .05 & .34 & .74 & .91 & .05 & .34 & .74 & .91 \\
B. Women naturally take much better care of & & & & & & & & \\
$\quad$ families than men do. & & & & & & & & \\
$\quad$ Agree & 1.0 & .86 & .72 & .43 & .96 & .86 & .43 & .00 \\
$\quad$ Disagree & .00 & .14 & .28 & .57 & .04 & .14 & .57 & 1.00 \\
C. A woman achieves through her husband's & & & & & & & & \\
$\quad$ career achievements. & & & & & & & & \\
$\quad$ Agree & .96 & .83 & .93 & .75 & .96 & .83 & .85 & .75 \\
$\quad$ Disagree & .04 & .17 & .07 & .25 & .04 & .17 & .15 & .25 \\
D. Women should raise children to have a & & & & & & & & \\
$\quad$ complete and happy life. & & & & & & & & \\
$\quad$ Agree & .88 & .01 & .85 & .08 & .88 & .01 & .85 & .08 \\
$\quad$ Disagree & .12 & .99 & .15 & .92 & .12 & .99 & .15 & .92 \\
E. Men can have a complete and happy life & & & & & & & & \\
$\quad$ without raising children. & & & & & & & & \\
$\quad$ Agree & .23 & .76 & .22 & .61 & .23 & .76 & .22 & .61 \\
$\quad$ Disagree & .66 & .24 & .66 & .31 & .77 & .24 & .78 & .39 \\
$\quad$ No opinion & .11 & .00 & .12 & .08 & & & & \\
\hline
\end{tabular}

I: I-Traditional type.

II-Non-child-oriented traditional type.

III-Child-oriented mixed type.

IV-Modern type.

Unlike Class II respondents, the Taiwanese respondents in Class III had high probabilities of agreeing with items B, C, and D but disagreeing with items $\mathrm{A}$ and $\mathrm{E}$. This group of respondents indicated a mixed type of genderrole attitudes with the endorsement of children's contribution to a complete and happy life (dubbed the "Child-oriented mixed type"). Of the Taiwanese respondents, 39 percent fit this category. Finally, those in Class IV had high probabilities of reporting positive attitudes toward items $\mathrm{C}$ and $\mathrm{E}$ but negative attitudes toward items A and D. Such respondents tended to have modern-oriented attitudes toward gender roles but did not think that children are important for them to pursue a complete and happy life. The probability of classifying respondents in Class IV, named the "Modern type," was .14.

The pattern of Latent Class Probabilities found in the Chinese data was similar to that in the Taiwanese data (Table 4). Following the same principle, the Chinese respondents in Classes I to IV were labeled the "Traditional type," "Child-oriented-traditional type," "Childoriented mixed type," and "Modern type," with probabilities of $.58, .13, .24$, and .05 , respectively.

In brief, the results of Latent Class Analysis revealed similar patterns of gender-role attitudes between Taiwan and China, including traditional, non-child-oriented traditional, child-oriented mixed, and modern types. Considering the differences in class probabilities 


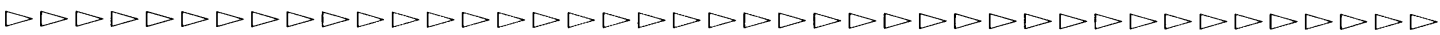

between Taiwan and China, however, Taiwanese were more likely than their counterparts in China to have mixed and modern attitudes toward gender roles. Looking into response probabilities between both data sets, among the people classified in mixed and modern types, Taiwanese were more likely than Chinese to support the statement that "women naturally take much better care of families than men do".

TABLE 5. MULTINOMIAL LOGISTIC REGRESSION ON GENDER-ROLE ATTITUDES: TAIWAN

$(N=2,174)$

\begin{tabular}{|c|c|c|c|c|c|c|}
\hline \multirow{2}{*}{ Variable } & \multicolumn{2}{|c|}{$\mathrm{L} 2$ vs. $\mathrm{L}^{1}{ }^{1}$} & \multicolumn{2}{|c|}{ L3 vs. L1 } & \multicolumn{2}{|c|}{ L4 vs. L1 } \\
\hline & $\beta$ & $\operatorname{Exp}(\beta)$ & $\beta$ & $\operatorname{Exp}(\beta)$ & $\beta$ & $\operatorname{Exp}(\beta)$ \\
\hline Intercept & -1.42 & & -.23 & & -1.32 & \\
\hline \multicolumn{7}{|l|}{ Current occupation } \\
\hline Administration & -.99 & .37 & $-.67 *$ & .51 & -.16 & .86 \\
\hline Professional workers & -.00 & .99 & $-.33^{\dagger}$ & .72 & -.30 & .74 \\
\hline Manual workers & -.08 & .92 & -.34 & .71 & .09 & 1.10 \\
\hline Farmers & -.00 & .99 & -.33 & .72 & .00 & 1.00 \\
\hline Unemployed and others & $-.66^{\dagger}$ & .52 & $-.85^{* * *}$ & .43 & $-.56^{*}$ & .57 \\
\hline Technological workers ${ }^{\mathrm{a}}$ & & & & & & \\
\hline Personal income & .00 & 1.00 & -.00 & .99 & -.00 & .99 \\
\hline Respondent's education & $.10^{* *}$ & 1.11 & $.07^{* * *}$ & 1.07 & $.13^{* * *}$ & 1.14 \\
\hline \multicolumn{7}{|l|}{ Marital status } \\
\hline $\begin{array}{l}\text { Married/living with partner } \\
\text { Never been married }\end{array}$ & .07 & 1.07 & .27 & 1.31 & -.03 & .97 \\
\hline Father's educational level & -.03 & .97 & .02 & 1.02 & -.00 & .99 \\
\hline \multicolumn{7}{|l|}{ Father's occupation } \\
\hline Administration & -.35 & .71 & $-.52 *$ & .60 & -.29 & .75 \\
\hline Professional worker & -.04 & .96 & .04 & 1.04 & .17 & 1.18 \\
\hline Manual worker & .16 & 1.18 & -.09 & .91 & -.18 & .84 \\
\hline Farmer & .25 & 1.28 & .33 & 1.39 & $.51^{\dagger}$ & 1.66 \\
\hline Unemployed and others & .85 & 2.34 & -.00 & .99 & .27 & 1.31 \\
\hline \multicolumn{7}{|l|}{ Technological worker ${ }^{\mathrm{a}}$} \\
\hline Mother's education & $.08^{*}$ & 1.08 & -.02 & .98 & -.05 & 1.00 \\
\hline Total number of children & $-.25^{*}$ & .78 & .01 & 1.01 & $-.18^{*}$ & .83 \\
\hline Family size & -.09 & .92 & -.03 & .97 & .00 & .96 \\
\hline \multicolumn{7}{|l|}{ Birth cohort } \\
\hline Born in 1949 or before & -.44 & .65 & -.19 & .82 & $-.45^{\dagger}$ & .64 \\
\hline Born 1950-1965 & -.13 & .88 & -.10 & .91 & .09 & 1.09 \\
\hline \multicolumn{7}{|l|}{ Born in 1966 or after } \\
\hline \multicolumn{7}{|l|}{ Gender } \\
\hline $\begin{array}{l}\text { Male } \\
\text { Female }^{\mathrm{a}}\end{array}$ & $-.92^{* *}$ & .40 & $-.36^{*}$ & .70 & $-.70^{* *}$ & .50 \\
\hline Urban experience (yes) & -.22 & .80 & -.12 & .89 & -.14 & .87 \\
\hline \multicolumn{7}{|l|}{ Interaction effect } \\
\hline Gender* personal income & -.00 & & .00 & & .00 & \\
\hline Pseudo $R$-square & .14 & & & & & \\
\hline
\end{tabular}

a. Reference category of the dummy variable.

t: $p<.10 ; *: p<.05 ; * *: p<.01 ; * * *: p<.001$

1: L1-Traditional type, L2-Non-child-oriented traditional type, L3-Child-oriented mixed type, L4Modern type. 


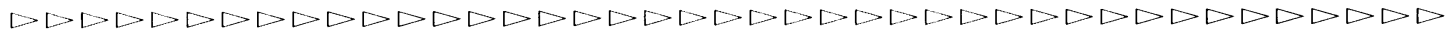

Effects on the Latent Classes of Gender-Role Attitudes

In this section, we discuss the factors explaining the different patterns of gender-role attitudes between the two societies. Multinomial logistic regression was used to investi- gate the effects of independent variables on the latent classes of gender-role attitudes. The latent class representing a traditional type (L1) was assigned as the baseline category for both data sets to understand how the effects of independent variables differed across the pat-

TABLE 6. MULTINOMIAL LOGISTIC REGRESSION ON GENDER-ROLE ATTITUDES: CHINA

$(N=2,217)$

\begin{tabular}{|c|c|c|c|c|c|c|}
\hline \multirow{2}{*}{ Variable } & \multicolumn{2}{|c|}{$\mathrm{L} 2$ vs. $\mathrm{L}^{1}$} & \multicolumn{2}{|c|}{ L3 vs. L1 } & \multicolumn{2}{|c|}{ L4 vs. L1 } \\
\hline & $\beta$ & $\operatorname{Exp}(\beta)$ & $\beta$ & $\operatorname{Exp}(\beta)$ & $\beta$ & $\operatorname{Exp}(\beta)$ \\
\hline Intercept & -1.92 & & -2.10 & & -2.96 & \\
\hline \multicolumn{7}{|l|}{ Current occupation } \\
\hline Administration & .06 & 1.07 & .07 & 1.07 & $1.08^{* *}$ & 2.94 \\
\hline Professional workers & -.01 & .99 & -.01 & .99 & -.03 & .97 \\
\hline Manual workers & -.09 & .91 & -.34 & .72 & -.34 & .71 \\
\hline Farmers & .27 & 1.31 & .23 & 1.26 & .43 & 1.53 \\
\hline Unemployed and others & .27 & 1.32 & .17 & 1.18 & -.40 & .67 \\
\hline \multicolumn{7}{|l|}{ Technological workers ${ }^{\mathrm{a}}$} \\
\hline Personal income & $-.31^{*}$ & .73 & $-.29 *$ & .75 & -.31 & .73 \\
\hline Respondent's education & .04 & 1.04 & $.09 * * *$ & 1.10 & $.08^{*}$ & 1.08 \\
\hline \multicolumn{7}{|l|}{ Marital status } \\
\hline $\begin{array}{l}\text { Married/living with partner } \\
\text { Never been married }\end{array}$ & -.30 & .74 & -.09 & .91 & .34 & 1.41 \\
\hline Father's educational level & -.01 & .99 & .01 & 1.01 & .02 & 1.02 \\
\hline \multicolumn{7}{|l|}{ Father's occupation } \\
\hline Administration & .25 & 1.28 & .01 & 1.02 & .02 & 1.02 \\
\hline Professional worker & .23 & 1.26 & .12 & 1.13 & .32 & 1.37 \\
\hline Manual worker & .39 & 1.48 & .10 & 1.11 & -.38 & .69 \\
\hline Farmer & $.52^{\dagger}$ & 1.69 & .32 & 1.38 & .59 & 1.80 \\
\hline Unemployed and others & -.14 & .87 & .27 & 1.31 & -.46 & .63 \\
\hline \multicolumn{7}{|l|}{ Technological worker ${ }^{\mathrm{a}}$} \\
\hline Mother's education & -.01 & .99 & .02 & 1.02 & -.03 & .98 \\
\hline Total number of children & $-.25^{*}$ & .78 & .04 & 1.04 & $-.29^{\dagger}$ & .75 \\
\hline Family size & -.01 & .99 & .03 & 1.02 & -.02 & .98 \\
\hline \multicolumn{7}{|l|}{ Birth cohort } \\
\hline Born in 1949 or before & .02 & 1.02 & -.24 & .78 & -.33 & .72 \\
\hline Born $1950-1965$ & -.12 & .88 & $-.35^{*}$ & .71 & $-.49^{\dagger}$ & .61 \\
\hline \multicolumn{7}{|l|}{ Born in 1966 or after ${ }^{\mathrm{a}}$} \\
\hline \multicolumn{7}{|l|}{ Gender } \\
\hline Male & $.47^{*}$ & 1.60 & -.10 & .91 & -.23 & .79 \\
\hline \multicolumn{7}{|l|}{ Female $^{\mathrm{a}}$} \\
\hline Urban experience (yes) & $.46^{*}$ & 1.58 & $.54^{* * *}$ & 1.29 & $.48^{\dagger}$ & 1.61 \\
\hline \multicolumn{7}{|l|}{ Interaction effect } \\
\hline Gender* personal income & $.29 *$ & & $.25^{*}$ & & .02 & \\
\hline Pseudo $R$-square & .10 & & & & & \\
\hline
\end{tabular}

a: Reference category of the dummy variable.

t: $p<.10 ; *: p<.05 ; * *: p<.01 ; * * *: p<.001$.

1: L1-Traditional type, L2-Non-child-oriented traditional type, L3-Child-oriented mixed type, L4Modern type. 
DDDDDDDDDDDDDDDDDDDDDDDDDDDDDDDDDDDDDDDD

terns of gender-role attitudes.

The common factors found significant in both data sets included respondents' occupation and education, and total number of children (Tables 5 and 6). Compared with technological workers, administrative workers in Taiwan were less likely to have child-oriented mixed attitudes, while administrative staffs in China were more likely to support modern attitudes. Taiwanese in the occupation category of "unemployed or other" were less likely to have child-oriented mixed or modern attitudes.

Better-educated respondents were, in both data sets, more likely than less-educated respondents to have egalitarian attitudes in terms of child-oriented mixed and modern types. The better educated in Taiwan were also more likely than the less educated to have non-child-oriented traditional attitudes. Moreover, greater numbers of children decreased the probability that one would express non-child-oriented traditional attitudes in both data sets. Taiwanese respondents who had more children were also less likely to support modern attitudes.

In addition to common factors, father's occupation, mother's education, and gender had main effects on gender-role attitudes in the Taiwanese data, while birth cohort, urban experience, and the interaction of personal income and gender did in the Chinese data. In Taiwan, those whose fathers were administrative staff were less likely than those whose fathers were technological workers to have child-oriented mixed attitudes. The respon-

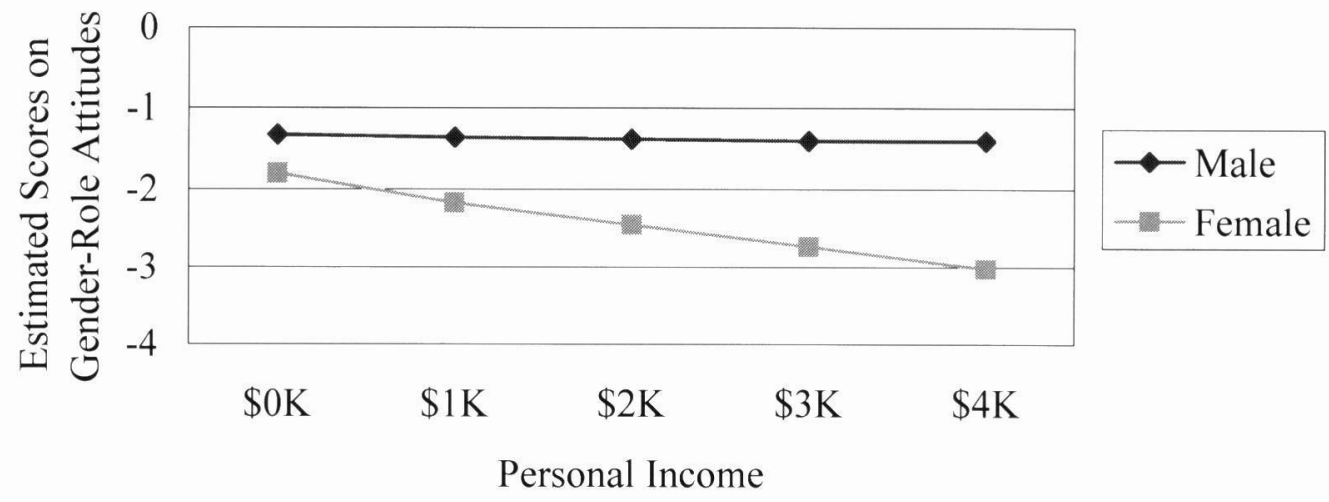

FIGURE 1. ESTIMATED SCORES ON GENDER-ROLE ATTITUDE L2 VS. L1, BY GENDER AND PERSONAL INCOME-CHINA

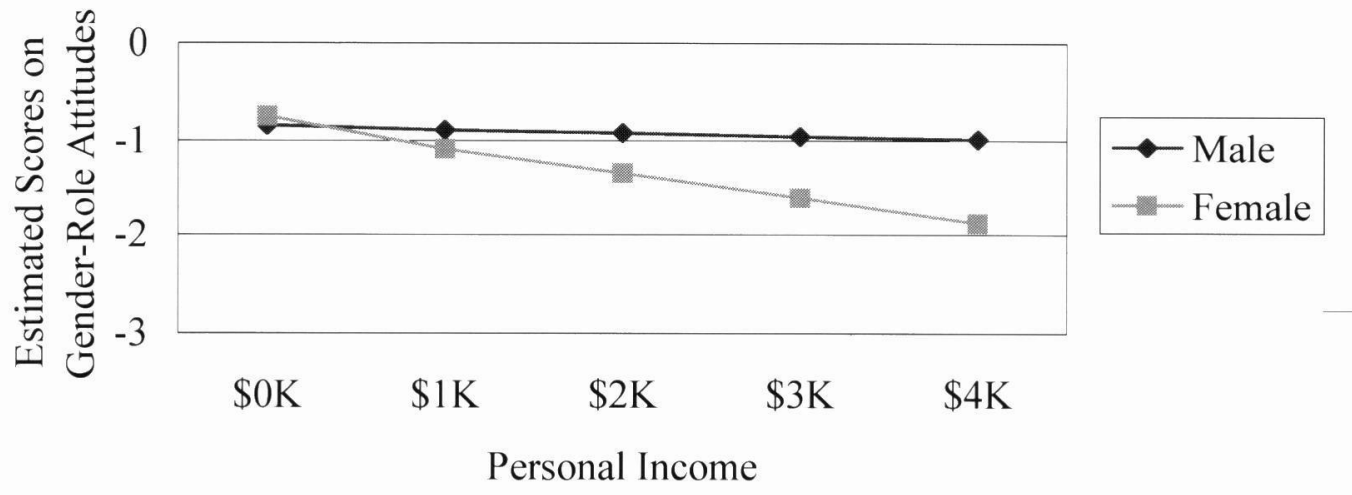

FIGURE 2. ESTIMATED SCORES ON GENDER-ROLE ATTITUDE L3 VS. L1, BY GENDER AND PERSONAL INCOME-CHINA 


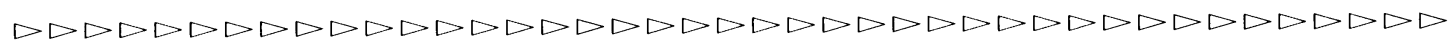

dents whose mothers were better educated were more likely than their counterparts to support non-child-oriented traditional attitudes. Finally, Taiwanese men were less likely than women to support non-child-oriented traditional, child-oriented mixed, or modern attitudes toward gender roles. In China, unlike Taiwan, urban experience was found to have a significant effect on gender-role attitudes. The respondents with urban experience were likely to have non-child-oriented traditional or child-oriented mixed attitudes. As expected, birth cohort was found to exert an effect on gender attitudes for Chinese born between 1950 and 1965. Chinese born during the period of 1950 to 1965 were less likely than their counterparts born in 1966 or after to support child-oriented mixed gender-role attitudes. The fluctuant effect did appear in China.

The relationship between personal income and gender-role attitudes varied with gender in China. The probabilities of being non-childoriented traditional or child-oriented mixed toward gender roles decreased as personal income increased for both women and men (Figures 1 and 2). Comparatively, the negative effect is more significant for women than for men.

\section{CONCLUSION AND DISCUSSION}

This study has examined the patterns and the important explaining factors behind gender-role attitudes between Taiwan and China. The analytical framework of the comparative study is based on a synthesis of resource exchange, family socialization, gender, cohort, and social-change perspectives. The results of Latent Class Analysis indicated that people in both Taiwan and coastal China have reached similar patterns of gender-role attitudes despite after some five decades of different cultural, social, economic, and political development. A model with four latent classes was developed to explain responses to five items of gender-role attitudes in both data sets. The classification of these latent classes resulted in a typology based on traditional/modern and the value orientation of having children for a "complete and happy life."
For the purpose of comparison, restrictions on conditional probabilities were imposed to examine the similarities of response patterns and of the latent class proportions across data sets. Despite the similar response patterns, comparable proportions of the Taiwanese respondents were classified into traditional and child-oriented mixed types, while more than half of the Chinese respondents, which were overrepresented with urban residents, were found likely to be supporters of traditional gender roles. The difference may partly be explained by the argument raised by Tang and Parish (2000) that the emergence of capitalism in a socialist society decreases the value orientation toward gender egalitarianism. It implies that in the beginning period of economic development in China, women may be more oriented toward family than work. Accordingly, the enforcement of effective progender-equality policies is difficult. However, the difference may also be attributed to contextual differences in the two societies. The issue that remains unexplored is why Communism and the Cultural Revolution in China did not produce sustained support of gender egalitarianism among the general public.

The results of multinomial logistic regression indicated that most of the predictors and the explanation power of the patterns of gender-role attitudes were consistent with previous studies. Different factors, however, were found in the two data sets. Common factors found significant in both data sets mostly affirmed resource exchange theory concerning education and family socialization theory in terms of childbearing experience. As expected, education was paramount in shaping one's modern gender-role attitudes and exerts more a significant effect in Taiwan than in China. The number of children tended to decrease one's non-child-oriented (mixed or traditional) attitudes, but it is to a more significant degree in Taiwan. In other words, having children is an essential element in distinguishing the two groups of traditional-oriented respondents in both societies.

Diverse findings were discovered on the effects of personal employment and childbear- 
ing on gender-role attitudes. Although an administrative job was more likely than a technological job to enhance modern attitudes in China, traditional attitudes were more likely to be held by administrative workers in Taiwan. Taiwanese in the "unemployed and other" sector tended to be traditional. The effect of employment status does not support the resource exchange theory in the case of Taiwan.

In addition to common factors, father's occupation, mother's education, and gender were found to produce significant effects on genderrole attitudes in Taiwan, while the effects of birth cohort, urban experience, and the interaction of personal income and gender were significant in coastal China. Consistent with previous studies (e.g. Brewster and Padavic, 2000), males were more likely to hold traditional gender-role attitudes. Our findings, however, support the idea that the size of the gender gap of gender-role attitudes may vary with societal context (Baxter and Kane, 1995). In particular, the distinct emphasis on the number of children and the rules of family policies between Taiwan and China may explain significant gender difference in genderrole attitudes found in Taiwan rather than in China. That is, China's one-child policy implies no gender effect on gender-role attitudes of Chinese, while Taiwan's flexible family planning implies child-oriented gender-role attitudes of Taiwanese. A father's administrative job was found unlikely to produce childoriented mixed attitudes, while mother's education increased non-child-oriented traditional attitudes toward gender roles. In other words, those in an administrative position were more likely to be authority oriented, and therefore traditional in father-child relations, while mother-education plays an important role in socializing children's gender attitudes.

As predicted, birth cohort was found significant in the Chinese data and appeared to have a fluctuant effect on the patterns of gender-role attitudes in China. Such a result partially echoes findings that the effect of age groups on family attitudes is much stronger in urban China than in urban Taiwan (Chang,
1998). In the present findings, the cohort effect may be attributable to the radical experiences before the Cultural Revolution. The experiences of those cohorts before the Cultural Revolution and after economic liberalization were important for maintaining traditionaloriented gender-role attitudes in China. Furthermore, urban living experience significantly and positively influenced traditional attitudes toward gender roles in coastal China, unlike in Taiwan. Moreover, the profound exploration of rural-urban difference in gender attitudes in China instead of coastal China is crucial and remains unexplored. As inferred from the present findings, future studies of gender-role attitudes are likely to find that rural residents are more traditional than respondents with rural experience.

The interaction effect of gender with personal income was significant when comparing traditional to two middle-ranged attitudes in China. That is, income independence does not necessarily result in women's egalitarian attitudes or men's traditional attitudes toward gender roles as suggested by the previous literature. This calls for a more thorough investigation of such interaction effects.

In conclusion, the findings of this study support that varying rates and forms of socioeconomic development to some degree differentiate individual attitudes toward gender roles, regardless of shared cultural heritage. The facts that the significant effects of urban experience and fluctuant effect of birth cohort were found only in China and that the effect of education was less significant in China than in Taiwan suggest that Beijing's dramatic changes in policy-making do have important implications for changes of gender-role attitudes in China. The smaller number of respondents in the mixed and modern types of child orientation and the smaller gender gap in gender-role attitudes in China than in Taiwan is partly a result of the one-child policy and other policies related to gender equality. In other words, the movement of collectivization that begin in the mid 1950s, the one-child policy first instituted in the late 1970 s, the neglect of educational equality since the reforms to- 


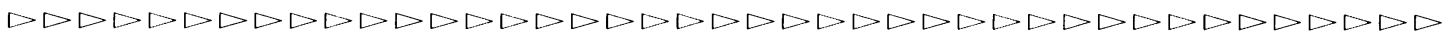

ward a market economy, and the clear difference in policy implementation between urban and rural China have had various and significant implications for the value orientation of residents of China.

By contrast, the progressive change of gender-role attitudes in Taiwan is due to a value change resulting from the island's continuous economic development and concomitant educational expansion. The socialization effects inferred from father's occupation and mother's education are found significant in Taiwan but not in China. Such findings support the argument that family organization is an agent interlocking the transformation of social structures with individual value (Thornton and Lin, 1994). Family policies in Taiwan emphasize the importance of kinship more than those in China. On the other hand, socialist ideology embedded in family policies in China has not been found in Taiwan. The policy difference between the Taiwanese straits may adequately explain why value orientation is more affected by family characteristics in Taiwan.

In order to foster understanding of societal difference in gender-role attitudes, a synthetic and multilevel framework is, in general, necessary for the further investigation of gender difference in gender-role attitudes across the Taiwan Strait. Two issues require further clarification: (1) whether men have felt threatened by the steady improvement and the radical progress of the ideology of gender equality in China and Taiwan, respectively, and (2) whether the different paces of progress have transformed male views, in particular, into gender egalitarianism. A time-series analysis on gender difference in the patterns of genderrole attitudes may be necessary to properly address these issues.

\section{【REFERENCES】}

Abbott D. A., Zheng F. M., Meredith W. H., 1995, “An evolving redefinition of the fatherhood role in the People's Republic of China," In Das M. S., Guta V. K. (ed.), Gender roles and family analysis, New Delhi: MD Publication Pvt Ltd., Chapter 12.

Baxter J., Kane E. W., 1995, "Dependence and inde- pendence: A cross-national analysis of gender inequality and gender attitudes," Gender \& Society, 9(2): 193-215.

Bielby D. D. V., Bielby W. T., 1984, "Work commitment, sex-role attitudes, and women's employment," American Sociological Review, 49: 234-247.

Brewster K. L., Padavic I., 2000, "Change in genderideology, 1977-1996: The contributions of intracohort change and population turnover," Journal of Marriage and the Family, 62: 477-487.

Cassidy M. L., Warren B. O., 1996, "Family employment status and gender role attitudes: A comparison of women and men college graduates," Gender \& Society, 10: 312-329.

Chang Y. H., 1998, "Family attitudes: A comparative study of urban China and Taiwan" (Chinese ed.), In Lau S.-K., Wan P.-S., Lee M.-K., Wong S.-L. (ed.), Changing Chinese Societies: Social indicator analysis, Hong Kong: Hong Kong Institute of Asia Pacific Studies, The Chinese University of Hong Kong.

Ciabattari T., 2001, "Changes in men's conservative gender ideologies: Cohort and period influences," Gender \& Society, 15: 574-591.

Dugger K., 1991, "Social location and gender role attitudes: A comparison of black and white women," In Lorber J., Farrell, S. A. (ed.), The social construction of gender, Newbury Park: Sage.

Eliason S. R., 1988, The Categorical Data Analysis System: Version 3.00a User's Manual, Pennsylvania State University, Department of Sociology and Population Issues Research Center.

Harris R. J., Firestone J. M., 1998, "Changes in predictors of gender role ideologies among women: A multivariate analysis," Sex Roles, 38: 239-252.

Huang L.W., 1998, "The attitudes toward gender division of domestic labor," (Chinese ed.), Bulletin of Sociology of Soochow University, 7: 81-111.

Hsieh K. H., Burgess R. L., 1994, "Marital role attitudes and expected role behaviors of college youth in mainland China and Taiwan," Journal of Family Issues, 15: 403-423.

Jacka T., 1997, Women's Work in Rural China: Change and Continuity in an Era of Reform, Cambridge: Cambridge University Press.

Kane P., 1995, "Population and family policies," In Benewick R., Wingrove P. (ed.), China in the 1990s, 


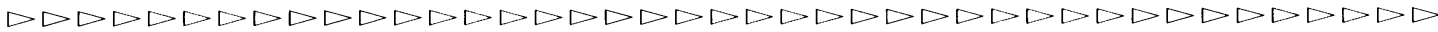

Vancouver, CAN: UBC Press.

Katsurada E., Sugihara Y., 1999, "Gender differences in gender-role perceptions among Japanese college students," Sex Roles, 41: 775-786.

Kulik L., 2002, “The impact of social background on gender-role ideology: Parents' versus children's attitudes," Journal of Family Issues, 23: 53-73.

Lott B., 1997, "The personal and social correlates of a gender difference ideology," Journal of Social Issues, 53: 279-298.

Mason K. O., Czajka J. L., Arber S., 1976, "Change in U.S. women's sex-role attitudes, 1964-1974," American Sociological Review, 41: 573-596.

Mason K. O., Lu Y.H., 1988, "Attitudes toward women's familial roles: Changes in the United States, 1977-1985," Gender \& Society, 2: 39-57.

Panayotova E., Brayfield A., 1997, "National context and gender ideology: attitudes toward women's employment in Hungary and the United States," Gender \& Society, 11: 627-655.

Plutzer E., 1988, “Work life, family life, and women's support of feminism," American Sociological Review, 53: 640-649.

Rai S. M., 1995, "Gender in China," In Benewick R., Wingrove P. (ed.), China in the 1990s, Vancouver, CAN: UBC Press.

Rice T. W., Coates D. L., 1995, "Gender role attitudes in the southern United States," Gender \& Society, 9: 744-756.

Tallichet S. E., Willits F. K., 1986, “Gender-role attitude change of young women: influential factors from a panel study," Social Psychology Quarterly, 49: 219-227.

Tang W., Parish W. L., 2000, Chinese Urban Life under Reform: The Social Contract, Cambridge, UK: Cambridge University Press.

Thoburn J., Howell J., 1995, “Trade and development: The political economy of China's open policy," In Benewick R., Wingrove P. (ed.), China in the 1990s, Vancouver, CAN: UBC Press.

Thornton A., Lin H. S., 1994, Social Change and the Family in Taiwan, Chicago: The University of Chicago Press.

Thornton A., Alwin D. F., Camburn D., 1983, "Causes and consequences of sex-role attitudes and attitude change," American Sociological Review, 48: 211-227.

Wilkie J. R., 1993, “Changes in U.S. men's attitudes toward the family provider role 1972-1989," Gender \& Society, 7: 261-279.

Wilson L. C., Smith C. Y., 1995, "Gender role perceptions in urban Guyana," In Das M. S., Guta V. K. (ed.), Gender Roles and Family Analysis, New Delhi: MD Publication Pvt Ltd.

Yamaguchi K., 2000a, "Multinomial logit latent-class regression models: an analysis of the predictors of gender-role attitudes among Japanese women," American Journal of Sociology, 105: 1702-1740.

Yamaguchi K., 2000b, “Married women's gender-role attitudes and social stratification: Commonalities and differences between Japan and the United States," International Journal of Sociology, 30: 5289.

Yi C. C., Kao S. G., 1986, Married Women's Attitudes toward Gender Roles (Chinese ed.), Working Paper Series No. 70, Institute for Social Sciences and Philosophy. Taipei, Taiwan: Academia Sinica. 